\title{
The acculturation, language and learning experiences of international nursing students: Implications for nursing education
}

\author{
Creina Mitchell*, Letitia Del Fabbro, Julie Shaw \\ School of Nursing and Midwifery, Menzies Health Institute Queensland, Griffith University, Southport, Queensland 4222, Australia
}

\section{ART ICLE INFO}

\section{Keywords:}

Professional education

Clinical teaching

Language

Student support

International students

Equity

Cultural competence

\begin{abstract}
A B S T R A C T
Background: International or foreign students are those who enrol in universities outside their country of citizenship. They face many challenges acculturating to and learning in a new country and education system, particularly if they study in an additional language.

Objectives: This qualitative inquiry aimed to explore the learning and acculturating experiences of international nursing students to identify opportunities for teaching innovation to optimise the experiences and learning of international nursing students.

Methods: Undergraduate and postgraduate international nursing students were recruited from one campus of an Australian university to take part in semi-structured interviews. A purposive and theoretically saturated sample of 17 students was obtained. Interviews were audio-recorded and field notes and interview data were thematically analysed.

Results: Expressing myself and Finding my place were the two major themes identified from the international student data. International nursing students identified that it took them longer to study in comparison with domestic students and that stress negatively influenced communication, particularly in the clinical setting. Additionally international nursing students identified the need to find supportive opportunities to speak English to develop proficiency. Clinical placement presented the opportunity to speak English and raised the risk of being identified as lacking language proficiency or being clinically unsafe. Initially, international nursing students felt isolated and it was some time before they found their feet. In this time, they experienced otherness and discrimination. Conclusions: International nursing students need a safe place to learn so they can adjust and thrive in the university learning community. Faculty and clinical educators must be culturally competent; they need to understand international nursing students' needs and be willing and able to advocate for and create an equitable environment that is appropriate for international nursing students' learning.
\end{abstract}

\section{Introduction}

The premise of this paper is that language acquisition and education acculturation are major challenges for international nursing students in achieving optimal student learning (Lum et al., 2015; Wang et al., 2008). Students who do not have a full grasp of the language and/ or the new education culture will not progress as well as those who do. Together these factors have the potential to impact the student experience of education, student learning outcomes, graduate attributes and consequently the quality of the practice of the novice registered nurse. Tertiary education institutions, nurse academics and nurse educators need to develop strategies that address these major challenges to pro- vide a safe place for students to learn, explore nursing knowledge and practice nursing safely (Crawford and Candlin, 2013; Shaw et al., 2015).

\section{Background}

Worldwide, students travel to further their education for secondary and/or tertiary educational experiences and qualifications. In the tertiary education sector, students who enrol in universities outside their country of citizenship, in either on-shore or offshore programs, are known as 'international students' (Arkoudis et al., 2012). International students have also been described as, 'foreign', or 'overseas' students.

\footnotetext{
* Corresponding author at: School of Nursing and Midwifery, Gold Coast Campus, Griffith University, 4222, QLD, Australia.

Email address: c.mitchell@griffith.edu.au (C. Mitchell)
} 
For the purpose of this discussion, they will be referred to as 'international' nursing students. Students native to the country of education will be referred to as 'domestic' students.

Globally, international student education is recognised as a major revenue raiser by universities and governments alike (Deloitte Access Economics, 2013; Group of Eight, 2014; Universities UK, 2015). Shortcomings in the Australian education of international students have been identified in response to fluctuations in student enrolment (Bradley et al., 2008). As competition for the international student dollar has increased the focus has been on improving the quality of the student experience from a variety of perspectives including language proficiency (Arkoudis et al., 2014; Heng, 2012), and education acculturation (Hickey, 2015; Shaw et al., 2007).

Proficiency in the language of instruction is important as communication is more than words. It is how the words are used within the language; the mode of language communication for example spoken, written and electronic; the context of use; and the manner of the language communication for example jargon, colloquial or formal (Wang et al., 2008). There is a variety of language proficiency definitions but no agreed definition (Arkoudis, 2014). Importantly, in Australia to work in the health professions, a Level 7.0 in each of the four components of the International English Language Testing System (IELTS); listening, reading, writing and speaking; is required (Australian Health Practitioner Regulation Agency, 2015). These requirements are similar to requirements for enrolment in university health programs although there may be slight variations, such as an overall IELTS (Academic) of 7.0 including no component less than 6.5. Nevertheless, students who meet the required pre-requisites still encounter language issues throughout their program of study (Lum et al., 2015; Wang et al., 2008). Academics who teach international nursing students have attempted to address English proficiency with varying degrees of success (Boughton et al., 2010; Glew, 2013).

Acculturation refers to the process whereby an individual, or group, adopt or adapt cultural traits of another group which may then result in new or blended cultural patterns/behaviours (Hickey, 2015). Acculturation of international students refers to international nursing students adopting beliefs and adapting behaviours of the new education culture in order to progress and succeed in their education program. To a certain extent, all students beginning studies require some support as they transition to university (Urquhart and Pooley, 2007), and acculturate to the new university context. For example, students from secondary education are confronted with new structures, support mechanisms, educational standards and academic expectations when they enter university education. International nursing students further adapt to different socio-cultural and communication norms, a new and different education system, and possibly a new language (Choi, 2005). This obvious difference for international nursing students indicates, from a student equity perspective, that academic staff need to consider extra support for these students (Boughton et al., 2010; Gilligan and Outram, 2012).

Providing for international nursing students in a culturally competent manner supports the inclusion of these students within the new education experience to create a sense of belonging (Levett-Jones et al., 2009). Cultural competence and cultural humility (Tervalon and Murray-Garcia, 1998) indicate the ability of an individual to interact effectively across cultures and refers to the ability of individuals and organisations, including the nursing profession and health and educational institutions, to enact cultural safety (National Health and Medical Research Council, 2005). Cultural safety refers to the provision of an environment where all are respected and work together towards shared goals including that of learning (Ramsden, 1990; Williams, 1999). Cultural competence and cultural safety go hand in hand. This may of course be difficult to enact especially if all staff and students are not aware of the concepts or capable of enacting them (Berman and
Paradies, 2010). Logically this means that without cultural competence and cultural safety international nursing students may experience both discrimination and racism in new social and education environments (Pettman, 1992; Sedgwick et al., 2014).

The impetus for the research project arose from concerns amongst staff at one Australian university campus that international nursing student learning needs, across both undergraduate and post-graduate programs, were not being optimally met. Such concerns regarding the learning and teaching of international students have been evident in the literature for a number of years (Choi, 2005; DeLuca, 2005). Investigations have focussed on quality improvement (Glew, 2013), relationships between staff and students (Levett-Jones et al., 2009), and commencing student issues. Others explored international student experience and needs, for example Carter and Xu (2007) thematically analysed survey results of 123 nursing students, academics $(n=14)$, and community advisors $(n=4)$ identifying key international student support needs. The identified needs related to student retention, admission criteria, student screening and faculty support, highlighting the structural influences affecting the international student experience, but leaving room for further investigation of the student experience.

Adding to this perspective Wang et al. (2008) identified obstacles to learning, learning experience, coping strategies, and desired academic assistance in their investigation of the learning experience of 21 Taiwanese postgraduate nursing students at one Australian university. Others identified the communication challenges of international nursing students (Crawford and Candlin, 2013; Lum et al., 2015). The study by Crawford and Candlin (2013) explored the language needs of culturally and linguistically diverse undergraduate nursing students in a small action research study, this paper highlighted the potential for action research in this milieu. The identified strategies related to English language acquisition and the challenging requirements of the English language testing exam.

Overall the research regarding the learning of international nursing students is fragmented. Taking these perspectives into account our exploration of the literature indicated the need to further develop understandings of the experience of international nursing students in order to address their equity needs.

\section{Methods}

This qualitative inquiry aimed to explore the learning and acculturation experiences of international nursing students studying within a School of Nursing and Midwifery at one Australian university. It aimed to address the question "how do international nursing students experience learning within a School of Nursing and Midwifery?" The study informed a larger participatory action research (PAR) project that aimed to promote enhanced experiences for international students (Del Fabbro et al., 2015; Shaw et al., 2015).

Data collection for this inquiry was designed to explore the student's experiences of learning and acculturation. A semi-structured interview guide was developed, reviewed by members of the research team, piloted with international nursing students then revised and finalised (DiCicco-Bloom and Crabtree, 2006). A sample list of open-ended interview questions is provided to illustrate the initial lines of inquiry (see Box 1). Participants undertook one group or individual face-to-face interview on campus. The opportunity to participate in a small group interview was offered to accommodate students who did not wish to be interviewed alone.

Purposive sampling was undertaken (Palys, 2008) and invitations to volunteer were sent to those identified as meeting the sample criteria; namely international undergraduates enrolled in a Bachelor of Nursing program and international postgraduates enrolled in Coursework or Higher Degree by Research nursing programs at one Australian university campus. International nursing students who responded to the writ- 


\section{Box 1. Examples of interview questions}

- What is it like to be a student in this School?

- What things have helped your learning here?

- Could you please tell us about your experiences of learning and teaching in Australia?

- What challenges do you face as an international student?

- What sort of activities do you undertake to support your use of the English language?

- Where do you get support?

- What makes you feel part of the overall student body at this University?

ten invitation to volunteer contacted the researchers directly and had an opportunity to discuss the research project before providing written consent to participate in the project.

Interviews, ranged from 30 to $60 \mathrm{~min}$ in length, were audio-recorded and interviewers made field notes during and after the interviews. Interviews were transcribed and researchers performed manual thematic analysis of the transcribed interviews and field notes (Basit, 2003). Analysis required systematically identifying and coding key elements and concepts, interpreting and re-categorizing data into sub-themes then major themes and was guided by methodological understandings of thematic analysis (Creswell, 2007; Ryan and Bernard, 2003; Vaismoradi et al., 2013). Two members of the research team independently undertook manual thematic analysis of the first five interviews and resolved coding differences by discussion and negotiation. Constant comparison of data was undertaken during data collection and sampling became theoretical as well as purposive (Guest et al., 2006). Maximum variation was reached after 15 interviews and two additional interviews were undertaken which confirmed data saturation had been reached. Data were de-identified during the transcription process by removal of names and personal information and stored securely in accordance with the research protocol. Research findings are presented with numeric not personal identifiers.

The University Human Research Ethics Committee granted ethical approval for the project. As it was possible that the researchers had teacher-learner relationships with the international nursing students enrolled in the School of Nursing and Midwifery, invitations to volunteer in the research were disseminated by administrative staff, on behalf of the researchers, in order to alleviate any perceived coercion to participate. Furthermore researchers only collected data from students they did not teach. In line with national research guidelines (National Health and Medical Research Council, 2007), participants were informed they were able to withdraw from the study at any time and a protocol was in place to refer any students for support if the interview process was to cause distress (DiCicco-Bloom and Crabtree, 2006).

\section{Results}

Seventeen (17) international nursing students were interviewed; the sample comprised 10 undergraduates and seven (7) post-graduates, all of which did not have English as their first language. Nine (9) interviews were conducted one-on-one and there were three (3) group interviews (2-3 participants). Two major themes were identified from the student data, Expressing myself and Finding my place.

\subsection{Expressing Myself}

This theme Expressing myself is about development of English language confidence and includes the overlapping elements of the time taken for international nursing students to feel confident and proficient in their use of the English language, the stress associated with this and the strategies that international nursing students used to find opportunities to practice speaking in English. The sub-themes that constitute this major theme include: Language - it takes time, Stress influences communication, and Finding opportunities for speaking English. Table 1 exemplifies the development of this theme, and illustrates the key coding elements and concepts, the sub-themes, the major theme and the relationships between coding and themes.

In the sub-theme of Language - it takes time participants described the way in which language developed over time, including dreaming in the English language. International nursing students compared their experience with that of domestic students, they were mindful of the extra time it took for them to study in comparison with domestic students. Engagement with complex anatomy and physiology language as well as medical terminology presented a specific challenge related to the Latin base of the language. International nursing students also had great difficulty with colloquialisms and the use of acronyms. They described a process whereby it took time to translate and work in the English language, including additional time needed to find the meaning of words or finding the right word within the learning situation.

"Sometimes I have the answer in my language but maybe I can't

find the one word."

"I need more time to read. Sometimes I need to think - translate to my language and think about it to understand it."

The sub-theme of Stress influences communication was apparent in the way participants described their interactions both in the classroom and the clinical area. International nursing students reported stress related to feeling pressure to answer questions in a large group environment, including as a result of the time taken to translate.

"Stressful times make translation more difficult."

“...sometimes, for example one of my professors asked me an easy question in class and I still couldn't answer her because she

Table 1

Building process for the major theme Expressing myself.

\begin{tabular}{lll}
\hline $\begin{array}{l}\text { Key coding elements and } \\
\text { concepts }\end{array}$ & Sub-themes & Major theme \\
\hline $\begin{array}{l}\text { At first it takes time to } \\
\text { translate and work in English }\end{array}$ & Language - it takes time & $\begin{array}{l}\text { Expressing } \\
\text { myself }\end{array}$ \\
$\begin{array}{l}\text { Finding the meaning/finding } \\
\text { the word }\end{array}$ & \\
$\begin{array}{l}\text { Dreaming in English } \\
\text { Understanding terminology }\end{array}$ & Stress influences \\
Easier without pressure & communication & \\
$\begin{array}{l}\text { Loss of language in times of } \\
\text { stress }\end{array}$ & & \\
$\begin{array}{l}\text { Stress and translation } \\
\text { Encourage me to participate }\end{array}$ & $\begin{array}{l}\text { Finding opportunities for } \\
\text { speaking English }\end{array}$ & \\
$\begin{array}{l}\text { Group work helps English } \\
\text { Clinical placement helps } \\
\text { English }\end{array}$ & & \\
\hline
\end{tabular}


suddenly asked me the question and I couldn't answer. Besides, at that moment everyone (my classmates) was waiting for my answer and I felt stressed."

Students identified the need for opportunities to speak English and this was part of the third sub-theme Finding opportunities for speaking English. Participants sought these opportunities in a number of ways within the university context, some participants also actively sought English-speaking opportunities outside of their university experience.

"University a good environment to improve English either by talking with international friends, domestic students or doing group assignments. When doing group work I would not think in Chinese I would think in English."

"I work in Meals on Wheels and nursing home as volunteer so that I can practice my English."

For undergraduate nursing students classroom experiences and clinical placements illuminated the need to focus on English language development. Clinical placements, within the context of university studies, provided the opportunity to practice English but also highlighted the need to be proficient at English.

"(During clinical placement) everything is English, the notes, the conversation, the handover and talking to patients and everyone."

"Placement is the best thing - it is the biggest learning opportunity... I have to talk with other people and I have to look after the patient."

Some students initially believed that their English was quite good, however, their clinical placement experience highlighted that they needed to work on their English language skills. In one case the experience of failing lead the student to focus on their communication skills.

"This experience (of failing clinical placement) was a good motivation for improving medical communication."

Overall the students identified that full participation in university life was key to developing English language proficiency. Group work and clinical placement opportunities were specifically identified as important strategies for acculturation, language and learning.

\subsection{Finding My Place}

The second major theme Finding my place, encapsulates the process that participants experienced in learning about their new study and living environment. The sub-themes that enmesh and constitute this theme include: Feeling isolated, Finding my feet, and Otherness and discrimination. The key coding elements and concepts informing these sub-themes and subsequently the major theme are exemplified in Table 2 .

The process of establishing oneself in a new university was recognised as an all-round challenging experience, and first year was identified as pivotal.

“...first year was very stressful... Every year is challenging but first year is everything. You have to find a job and study. Everything."
Table 2

Building process for the major theme Finding my place.

\begin{tabular}{lll}
\hline Key coding elements and concepts & Sub-themes & $\begin{array}{l}\text { Major } \\
\text { theme }\end{array}$ \\
\hline Going alone & Feeling isolated & $\begin{array}{l}\text { Finding my } \\
\text { place }\end{array}$ \\
$\begin{array}{l}\text { I isolate myself } \\
\text { I don't care what others think any } \\
\text { more }\end{array}$ & Finding my feet \\
$\begin{array}{l}\text { Australia is different } \\
\text { Hesitand to answer at first }\end{array}$ & \\
$\begin{array}{l}\text { Prejudice and blaming } \\
\text { Feeling excluded by student peers/ } \\
\text { rude attitude of student peers } \\
\text { Cultural differences in } \\
\text { communication }\end{array}$ & Otherness and \\
\end{tabular}

International nursing students described the experience of overcoming hurdles including isolation. Participants spoke about feeling isolated which resulted from choices they made to keep to themselves. Keeping a distance from peers was associated with a desire to 'save face' or resulted from not feeling comfortable to speak in public and was a strategy to prevent embarrassment. Participants identified that they changed over time, they described their initial hesitation and fears, and identified that they gained confidence, often with help from support staff and academic staff (3.

"At first I was too scared to talk to anyone because I come from different country, language, culture ...umm, maybe I will do something wrong."

"Initially worried about what others will think (of them) but not so worried in third year."

The next sub-theme of Otherness and discrimination arose from participants' stories of experiencing discrimination in the class room, during clinical placement and when trying to find work in the community.

"I don't know why the Australian students do not want to interact with us. I feel like they are avoiding interaction with me."

"Sometimes in group work with Australian students I don't feel involved for example, they don't include me in group planning meetings ..."

"It's something that I don't understand why the Australian students don't want to work with me."

These experiences highlighted the position of powerlessness that international students find themselves in when they encounter discrimination.

Table 3

Major themes and sub-themes.

\begin{tabular}{ll}
\hline Expressing myself & Finding my place \\
\hline Language - it takes time & Feeling isolated \\
Stress influences communication & Otherness and discrimination \\
Finding opportunities for speaking English & Finding my feet \\
\hline
\end{tabular}


"I have experiences of being spoken to rudely by students ... An Australian student said...Can you understand English? Just move. This was because ...the Australian student wanted (her seat)."

"We did not have a way to resolve this."

Another example illustrated how misunderstandings occur as a result of cultural language differences.

“...when I talk to my professor I don't say the 'please'. This caused some problems with the lecturers - they thought I was ordering them around."

The third sub-theme Finding my feet identified strategies that were helpful for acculturation. Friends were an important support and the library was identified as an important space for interpersonal support and building confidence to study.

"Many things have helped, facilities, and people. The library, Internet access and lecturers."

"At first it was difficult but we can find out how to approach questions and then I can go to the library myself. Now I find out $90 \%$ of the information for my learning myself. In my country we get given the information, the method here is better for my learning."

The early provision of lecture notes and the open door access to lecturers were identified as supportive for the international participants.

"This lecturer very good at explaining and answering questions about things I did not understand."

Overall it took time for students to learn about a new education system and how to study effectively in a new country. From when they first arrived to study in Australia, they were hesitant and fearful, and experienced discriminatory behaviours. This highlighted cultural differences between international nursing students' behaviour and the expectations present in their new study environment that required mediation and supportive responses to be understood. With time they found their place however it required personal effort and it was not without personal cost.

"It is difficult for international students as ... we need to work so we do not have time to go to parties and socialise."

It is hard to do well academically as "...it is out of your control...due to timing and access (to information and support services)"

\section{Discussion}

Expressing myself and Finding my place are the two major themes that describe international nursing students' experiences of studying in a new country. Each major theme comprises three distinct but related sub-themes (Table 3 ). In this analysis, themes incorporate aspects that could be considered supporting or hindering.INSERT TABLE 3 HERE
Pivotal to the Expressing myself theme is the sub-theme of language. The existing literature on international students identifies language as a precursor for adjustment (Andrade, 2006). In this study, language development occurred in parallel with acculturation or Finding my place.

\subsection{Finding Opportunities for Speaking English}

Participants identified supports or strategies that were helpful for English language development. These included class participation, on the proviso that the student was not required to be the focus of the class. Hence small group work was identified as preferential to whole class presentations. Although our findings identified group work as a strategy, the focus of research to date has been on the usefulness of English language support programs in aiding international nursing students engaged in higher education (Crawford and Candlin, 2013). At the time of our study, the university did not mandate that international nursing students undertake English language programs and interestingly, international nursing students did not suggest this as an option, possibly as they only identified what they had experienced.

Similar to our findings the clinical area has been identified as a key opportunity to speak English (Edgecombe et al., 2013). Interestingly our findings also identified that international nursing students were aware that learning in the clinical setting highlighted deficiencies in their English speaking abilities creating risks in the successful completion of practicum. Essentially clinical practice as a learning strategy is a double-edged sword for international nursing students. Our findings illustrate the need for students to develop the courage and the confidence to express themselves in the clinical environment however, this must occur in conjunction with sufficient English proficiency for safety in the clinical environment.

\subsection{Otherness and Discrimination}

This research highlights that, in the classroom and clinical learning environments, international nursing students may experience 'otherness' as participants in an ethnocentric curriculum. This experience of 'otherness' highlights the presence of pervasive institutional racism and discrimination (Paradies et al., 2013), an experience where race and culture are significant 'in determining access to... institutions and to their resources' (Pettman, 1992, p. 58). For international nursing students this may manifest in numerous ways, as highlighted by the results of this research, as part of university campus interactions, in clinical experience environments and in their social/private lives. Implementing cultural competency principles is key to improving the experience of international nursing students and other 'outsider' participants in the curricula (DeBrew et al., 2014).

Whilst cultural competency is a routinely articulated ethos of the institutions that international nursing students encounter within their acculturation journey, there remains an opportunity to further develop or enhance mechanisms for mediating the experience of international nursing students. Models of clinical simulation are used to provide comprehensive nursing experience, expanding on clinical skill practices to include management issues (Hawkins et al., 2008) and advanced decision making (Levett-Jones et al., 2009). This research suggests an opportunity to ensure that learning environments, especially case study and clinical simulation, specifically foster and facilitate cultural competency in a reflexive and reflective way.

Academic nursing staff have a role to play in partnering with clinicians and industry to develop models and practices of effective clinical teaching and coaching (Benner et al., 2010). For international nursing students effective clinical coaching may be enhanced via improved cognisance of the struggles, in particular language and acculturation, that international nursing students experience in transition to the clini- 
cal environment. Combined innovations in university teaching and clinical coaching (Kelton, 2014) along with culturally competent clinical facilitators have the potential to improve the acculturation experience of international nursing students and imbue learning experiences with a sense of student belonging (Mattila et al., 2010) by equitably supporting international nursing students. Support includes advocating for the international nursing students' experience of clinical practice to ensure access to learning resources and opportunities as well as a safe environment. Effectual clinical facilitators are known to be role models who are supportive, have sound reasoning skills, the ability to be empathetic and hold nursing in high regard (Montenery et al., 2013).

As a small single site qualitative inquiry, this study was not expected to produce generalizable results (Daly et al., 2007) however by adhering to well accepted qualitative methods, and describing the context and methods of the study, readers can assess the transferability of findings to their own or other contexts. Verbatim quotations were provided to capture the voices of international nursing students, explain the phenomena and enable the reader to assess the evidence collected during the inquiry (Corden and Sainsbury, 2006) which adds to the overall authenticity, validity and credibility of the study (Whittemore et al., 2001).

This study highlights the importance of recognising and addressing the challenges that international students face when studying nursing, and furthermore brings to light strategies that may assist students meet these challenges including the need for socialisation opportunities inside and outside of the university classroom and early access to course materials. Furthermore, our findings may be applicable to other practice based disciplines that require their students to undertake placement within clinical environments. It is recommended that future research assess these strategies as well as further investigate the experience and needs of international nursing students undertaking clinical practicum.

\section{Conclusions}

This study reported on the experiences of international nursing students studying at one campus of an Australian university. The study findings replicate and provide support for some findings that have already been identified; specifically that language acquisition and acculturation are important for international student learning. The study highlights the need for international nursing students to have time to learn in a place that is safe so as to thrive in the university learning community. Teachers of international nursing students, both academic and clinical, need to be cognizant of the 'otherness' of international nursing students, develop cultural competence and a willingness to advocate for an equitable environment that is appropriately resourced for international nursing students' learning opportunities. In particular teachers are advised to develop strategies that are inclusive of international nursing students to negate discriminatory practices, with cultural humility being not only studied but also demonstrated and practiced so that students, both international and domestic, have the opportunity to develop the necessary skills to address discrimination in a professional manner and enhance learning opportunities.

\section{Acknowledgements}

A Griffith Health Group Learning and Teaching Grant funded this project.

\section{References}

Andrade, M., 2006. International students in English-speaking universities: adjustment factors. J. Res. Int. Educ. 5 (2), 131-154. http://dx.doi.org/10.1177/ 1475240906065589
Arkoudis, S., 2014. Integrating English Language Communication Skills Into Disciplinary Curricula: Options and Strategies. Australian Government, Sydney, Australia. Retrieved from: http://www.cshe.unimelb.edu.au/research/teaching/integ eng/.

Arkoudis, S., Baik, C., Marginson, S., Cassidy, E., 2012. Internationalising the student experience in Australian tertiary education: developing criteria and indicators. In: Australian Education International. Retrieved from: http://www.cshe.unimelb.edu.au/.

Arkoudis, S., Baik, C., Bexley, E., Doughney, L., 2014. English Language Proficiency and Employability Framework: For Australian Higher Education Institutions. Australian Government, Canberra, ACT. Retrieved from http://www.cshe.unimelb.edu. au/research/teaching/docs/ELP Employability_Framework_Final_Report_181114.pdf.

Australian Health Practitioner Regulation Agency, 2015. English language skills registration standard. Retrieved from http://www.ahpra.gov.au/Registration/ Registration-Standards/English-language-skills.aspx

Basit, T., 2003. Manual or electronic? The role of coding in qualitative data analysis. Educ Res. 45 (2), 143-154. http://dx.doi.org/10.1080/0013188032000133548.

Benner, P., Sutphen, M., Leonard, V., Day, L., 2010. Educating Nurses: A Call for Radical Transformation. Jossey-Bass, San Francisco, Ca..

Berman, G., Paradies, Y., 2010. Racism, disadvantage and multiculturalism: towards effective anti-racist praxis. Ethnic Racial Stud. 33 (2), 214-232. http://dx.doi.org/10. 1080/01419870802302272.

Boughton, M.A., Halliday, L.E., Browne, L., 2010. A tailored program of support for culturally and linguistically diverse (CALD) nursing students in a graduate entry masters of nursing course: a qualitative evaluation of outcomes. Nurse Educ. Pract. 10 (6), 355-360. http://dx.doi.org/10.1016/j.nepr.2010.05.003.

Bradley, D., Noonan, P., Nugent, H., Scales, B., 2008. Review of Australian Higher Education: Final Report. Australian Government, Canberra, Australia. Retrieved from: https: //education.gov.au/higher-education-publications.

Carter, K.F., Xu, Y., 2007. Addressing the hidden dimension in nursing education: promoting cultural competence. Nurse Educ. 32 (4), 149-153. http://dx.doi.org/10.1097/01. NNE.0000281085.58335.0e.

Choi, L.L.S., 2005. Literature review: issues surrounding education of English-as-a-Second Language (ESL) nursing students. J. Transcult. Nurs. 16 (3), 263-268. http://dx.doi. org/10.1177/1043659605274966.

Corden, A., Sainsbury, R., 2006. Using Verbatim Quotations in Reporting Qualitative Social Research: Researchers' Views. Social Policy Research Unit, University of York, York. Retrieved from http://php.york.ac.uk/inst/spru/pubs/ipp.php?id=180.

Crawford, T., Candlin, S., 2013. Investigating the language needs of culturally and linguistically diverse nursing students to assist their completion of the bachelor of nursing programme to become safe and effective practitioners. Nurse Educ. Today 33 (8), 796-801. http://dx.doi.org/10.1016/j.nedt.2012.03.005

Creswell, J.W., 2007. Qualitative Inquiry and Research Design: Choosing Among the Five Approaches, 2nd ed. Sage, London, England.

Daly, J., Willis, K., Small, R., Green, J., Welch, N., Kealy, M., Hughes, E., 2007. A hierarchy of evidence for assessing qualitative health research. J. Clin. Epidemiol. 60 (1), 43-49. http://dx.doi.org/10.1016/j.jclinepi.2006.03.014.

DeBrew, J., Lewallen, L., Chun, E., 2014. Outsiders in nursing education: cultural sensitivity in clinical education. J. Prof. Nurs. 30 (2), 149-154. http://dx.doi.org/10.1016/j profnurs.2013.08.005

Del Fabbro, L., Mitchell, C., Shaw, J., 2015. Learning among nursing faculty: insights from a participatory action research project about teaching international students. J. Nurs. Educ. 54 (3), 153-158. http://dx.doi.org/10.3928/01484834-20150218-12.

DeLuca, E., 2005. Crossing cultures: the lived experience of Jordanian graduate students in nursing: a qualitative study. Int. J. Nurs. Stud. 42 (6), 657-663. http://dx.doi.org/ 10.1016/j.ijnurstu.2004.09.017.

DiCicco-Bloom, B., Crabtree, B.F., 2006. The qualitative research interview. Med. Educ. 40 (4), 314-321. http://dx.doi.org/10.1111/j.1365-2929.2006.02418.x.

Deloitte Access Economics, Feb, 2013. The Economic Contribution of International Students. Australian Council for Private Education and Training. Retrieved from: http: //www.acpet.edu.au/uploads/files/Reports_Submissions/2013/ Economic-Contribution-Executive-Summary.pdf.

Edgecombe, K., Jennings, M., Bowden, M., 2013. International nursing students and what impacts their clinical learning: literature review. Nurse Educ. Today 33 (2), 138-142. http://dx.doi.org/10.1016/j.nedt.2012.07.015.

Gilligan, C., Outram, S., 2012. Culturally and linguistically diverse students in health professional programs: an exploration of concerns and needs. Educ. Health 25 (1), 40-47. http://www.edu.educationforhealth.net/text.asp?2012/25/40/99205.

Glew, P.J., 2013. Embedding international benchmarks of proficiency in English in undergraduate nursing programmes: challenges and strategies in equipping culturally and linguistically diverse students with English as an additional language for nursing in Australia. Collegian 20 (2), 101-108. http://dx.doi.org/10.1016/j.colegn.2012.04. 002 .

Group of Eight, 2014. Policy note: international students in higher education and their role in the Australian economy. Retrieved from: https://go8.edu.au/sites/default/files/ docs/publications/international_students_in_higher_education_and_their_role_in_the_ australian economy.pdf

Guest, G., Bunce, A., Johnson, L., 2006. How many interviews are enough?: an experiment with data saturation and variability. Field Methods 18 (1), 59-82. http://dx.doi.org/ $10.1177 / 1525822 \times 05279903$

Hawkins, K., Todd, M., Manz, J., 2008. A unique simulation teaching method. J. Nurs. Educ. 47 (11), 524-527. http://dx.doi.org/10.3928/01484834-20081101-04.

National Health and Medical Research Council, 2005. Cultural Competency in Health: A Guide for Policy, Partnerships and Participation. National Health and Medical Research Council, Canberra. Retrieved from: https://www.nhmrc.gov.au/ guidelines-publications/hp19-hp26. 
National Health and Medical Research Council, 2007. National Statement on Ethical Conduct in Human Research. NHRMC, Commonwealth of Australia. Retrieved from http: //www.nhmrc.gov.au/guidelines-publications/e72.

Heng, C.S., 2012. Defining English language proficiency for Malaysian tertiary education: past, present and future efforts. Adv. Lang. Lit. Stud. 3 (2), 150-160. http://dx.doi. org/10.7575/aiac.alls.v.3n.2p.150.

Hickey, P.J., 2015. One of these things is not like the others: assimilation, acculturation, education. Engl. J. 104 (5), 107-109. Retrieved from: http://www.ncte.org/journals/ ej/issues/v104-5.

Kelton, M.F., 2014. Clinical coaching-an innovative role to improve marginal nursing students' clinical practice. Nurse Educ. Pract. 14 (6), 709-713. http://dx.doi.org/10. 1016/j.nepr.2014.06.010.

Levett-Jones, T., Lathlean, J., Higgins, I., McMillan, M., 2009. Staff-student relationships and their impact on nursing students' belongingness and learning. J. Adv. Nurs. 65 (2), 316-324. http://dx.doi.org/10.1111/j.1365-2648.2008.04865.x.

Lum, L., Dowedoff, P., Bradley, P., Kerekes, J., Valeo, A., 2015. Challenges in oral communication for internationally educated nurses. J. Transcult. Nurs. 26 (1), 83-91. http:// dx.doi.org/10.1177/1043659614524792.

Mattila, L., Pitkäjärvi, M., Eriksson, E., 2010. International student nurses' experiences of clinical practice in the Finnish health care system. Nurse Educ. Pract. 10 (3), 153-157. http://dx.doi.org/10.1016/j.nepr.2009.05.009.

Montenery, S.M., Jones, A.D., Perry, N., Ross, D., Zoucha, R., 2013. Cultural competence in nursing faculty: a journey, not a destination. J. Prof. Nurs. 29 (6), e51-e57. http:// dx.doi.org/10.1016/j.profnurs.2013.09.003.

Palys, T., 2008. Purposive sampling. In: Given, L. (Ed.), Sage Encyclopedia of Qualitative Research Methods [Electronic Version]. Sage.

Paradies, Y., Truong, Priest, N., 2013. A systematic review of the extent and measurement of healthcare provider racism. J. Gen. Intern. Med. 29 (2), 364-387. http://dx.doi. org/10.1007/s11606-013-2583-1.

Pettman, J., 1992. Living in the Margins: Racism, Sexism and Feminism in Australia. Allen \& Unwin, North Sydney, NSW.

Ramsden, I., 1990. Cultural safety. N. Z. Nurs. J. 83 (11), 18-19.
Ryan, G.W., Bernard, H.R., 2003. Techniques to identify themes. Field Methods 15 (1), 85-109. http://dx.doi.org/10.1177/1525822x02239569.

Sedgwick, M., Oosterbroek, T., Ponomar, V., 2014. "It all depends": how minority nursing students experience belonging during clinical experiences. Nurs. Educ. Perspect. 35 (2), 89-93. http://dx.doi.org/10.5480/11-707.1.

Shaw, J.M., Moore, P.J., Gandhidasan, S., 2007. Educational acculturation and academic integrity: outcomes of an intervention subject for international post-graduate students in Public Health. J. Acad. Lang. Learn. 1 (1), A-55-A-66. Retrieved from http:// journal.aall.org.au/index.php/jall/article/view/23.

Shaw, J., Mitchell, C., Del Fabbro, L., 2015. Group work: facilitating the learning of international and domestic undergraduate nursing students. Educ. Health 28 (2), 124-129.

Tervalon, M., Murray-Garcia, J., 1998. Cultural humility versus cultural competence: a critical distinction in defining physician training outcomes in multicultural education. J. Health Care Poor Underserved 9 (2), 117-125.

Universities UK, 2015. The economic role of UK universities. Retrieved from: http:// www.universitiesuk.ac.uk/highereducation/Documents/2015/ TheEconomicRoleOfUKUniversities.pdf

Urquhart, B., Pooley, J., 2007. The transition experience of Australian students to university: the importance of social support. Aust. Community Psychol. 19 (2), 78-91. Retrieved from http://ro.ecu.edu.au/ecuworks/1366/.

Vaismoradi, M., Turunen, H., Bondas, T., 2013. Content analysis and thematic analysis: implications for conducting a qualitative descriptive study. Nurs. Health Sci. 15 (3), 398-405. http://dx.doi.org/10.1111/nhs.12048.

Wang, C., Singh, C., Bird, B., Ives, G., 2008. The learning experiences of Taiwanese nursing students studying in Australia. J. Transcult. Nurs. 19 (2), 140-150. http://dx.doi. org/10.1177/104365960731296.

Whittemore, R., Chase, S.K., Mandle, C.L., 2001. Validity in qualitative research. Qual. Health Res. 11 (4), 522-537. http://dx.doi.org/10.1177/104973201129119299.

Williams, R., 1999. Cultural safety- what does it mean for our work practice?. Aust. N. Z. J. Public Health 23 (2), 213-214. http://dx.doi.org/10.1111/j.1467-842X.1999. tb01240.x. 